\title{
Articulators for Thinking Modes of the Derivative from a Local Perspective
}

\author{
Irma Ercira Pinto-Rojas ${ }^{a}$ \& Marcela Parraguez ${ }^{\mathrm{b}}$ \\ aDeparment of Mathematic, Universidad Católica del Norte, CHILE \\ ${ }^{b}$ Mathematics Institute, Pontificia Universidad Católica de Valparaíso, CHILE
}

The purpose of this paper is to show and validate a design for a deep understanding of the derivative from its local perspective. Based on a historical and epistemological study of the derivative, we performed an extension of the Sierpinska theoretical framework Thinking Modes- of the domain of the derivative from its local perspective, and therefore identified three ways of thinking about the derivative, described as the Synthetic-Geometric-Convergent (SGC), Analytic-Operational (AO) and AnalyticStructural (AE, for its name in Spanish), as the components that, along with its articulators comprise a design for deep understanding of its local aspect. Methodologically, hypothetically proposed articulators are compared to data obtained in case studies with two groups of university students, in addition to a semi-structured interview to mathematicians, researchers and scholars, through which the proposed articulators elements were validated and clarified. The result is a design for the understanding of the derivative from its local aspect as a viable tool to cause the rupture from a purely algebraic thinking about this topic, and that benefits its deep understanding, being this, the ability of a student to articulate these thinking modes.

KEYWORDS

Derivative, thinking modes, understanding, articulators, local perspective

\section{ARTICLE HISTORY}

Received 10 August 2017

Revised 28 September 2017 Accepted 15 November 2017

\section{Introduction}

The concept of the derivative is a relevant topic for university study programs for first year students of sciences, engineering and other majors, and its understanding broadly researched.

\section{CORRESPONDENCE Irma Pinto-Rojas $\square$ ipinto@ucn.cl}

๑) 2017 I. Pinto-Rojas \& M. Parraguez.

Open Access terms of the Creative Commons Attribution 4.0 International License apply. The license permits unrestricted use, distribution, and reproduction in any medium, on the condition that users give exact credit to the original author(s) and the source, provide a link to the Creative Commons license, and indicate if they made any changes. (http://creativecommons.org/licenses/by/4.0/) 
Currently, (Jaafar and Lin, 2017; Tallman,Carlson, Bressoud and Pearson, 2016), evidence a range of difficulties from different theoretical approaches.

However, the understanding of this mathematical notion from a local perspective remains an open problem. One of the greater researched aspects associated to the understanding of the derivative is its algorithmic use and algorithmic practice.

Nevertheless, Artigue (1995) presents results which show that students, when faced with problems with derivatives, give priority to a use that is not supported by a conceptual understanding of the derivative, but rather on the definition of the derivative as limit. According to Zandieh (2000), multiple graphic, verbal, symbolic and other representations present also problems for the students, as they can think of the derivative as the slope of a straight tangent line, as an instant exchange rate, as the limit of the quotient difference, as the limit of the slopes of the secant lines. However, the connections between these notions from a local perspective are not clearly observed in their arguments.

Although Kinley (2016) shows that students have a vague concept of the algebraic notions related to geometrical interpretations, there is no evidence of other inquiries that consider the derivative as the best approach to the curve point through a component that clearly describes the understanding of this topic from a local perspective. Sánchez-Matamoros, García y Llinares (2008), present a review of researches focused on cognition elements for the understanding of the derivative, showing evidence that the graphic and analytical understanding of it is considered with unrelated algorithms. In this sense, (Ferrini-Mundi and Graham, 1994) they have also identified obstacles in the graphic understanding of the derivative of a function in a point, showing that is confusing for students to differentiate between the median speed and instant speed.

This fact calls for an in-depth inquiry of the derivative from its local perspective. In this context -speeds- Badillo, Azcárate and Font (2011), notes that this confusion is due to students having difficulties with the median exchange rate and the instant exchange rate.

Another research -Sfard (1991) - notes that students use the notion of the derivative as the slope of the straight tangent line (graphic) or as the limit of the secants (analytical), without establishing any type of connection between both, which weakens the response ability of students in tasks with the derivative in its local aspect. In this sense, Park (2015), analyzing the discourse of students, expresses that there is little explanation of local properties of real functions with real variables, which can contribute to a mixed conception between the meaning of the derivative as specific object in a point and in the vicinities of a point, but a relation between both has not been observed.

Recently, Vanderbrouck (2011) pointed that when university students begin their work with functions they have to adopt a local perspective about functions, a conception that is not built in High School, and it is accepted that 1 is the limit of 0,$9 ; 0.99 ; 0,999 \ldots$ which constitutes an epistemological obstacle that is often unnoticed when teaching the limit (Sierpinska, 1985; Mena, Mena, Montoya, Morales y Parraguez, 2015), and leaving it as a conceptual challenge for students since they learn rules about limits often without understanding why they work. 
The local perspective that we have been announcing in previous paragraphs, can initially be focused from an explanation in the system of real numbers, related to the infinitely small, which appears not to be considered in the teaching of real numbers -in fact the local definition is also confused with a dynamic explanation of the derivative- which further obstructs the understanding of derivative in its local aspect. Along this line, Pino-Fan, Godino y Font (2011), show from text analysis that the use of the incremental notation $\frac{\Delta y}{\Delta x}$, requires students to show an understanding of the local aspect of the derivative, this is, a semiotic complexity as stated by D'Amore and Godino (2007), of the derivative as limits of median variation rates.

With this background, it is possible to identify relationships between the different interpretations that describe the understanding of the derivative from a local perspective, which is the interest of this document. This is, to show evidence with the support of inquiry theory, on the concept of the derivative from its local aspect, as a perspective centered around which "makes the function in a point and its vicinity", with basis in an epistemological analysis that will allow for the articulation of a route of the cognitive activity of students with the understanding of this concept.

The questions formulated to address this problem were the following: Which mathematical elements do students bring into play to relate different interpretations of the derivative in its local aspect, when they solve problems with derivatives? Which interpretations of the derivative do students prioritize to solve these problems? Which mathematical elements allow for the articulation of different forms of interpreting the local aspect of the derivative?

To answer these questions, our research considered an epistemological analysis of the concept of the derivative from its local aspect, with the purpose of identifying the obstacles that must be overcome for its understanding. The first findings of our inquiry indicated that we needed to consider the theoretical framework of Sierpinska (2000) as an ad hoc reference, since it provided theoretical reference elements that allowed to raise theoretical and practical thinking modes of the derivative in its local perspective, as complementary epistemological categories (Sierpinska 2005).

We hope the presentation of this study contributes to the discussion about the understanding of the derivative in its local aspect, considering that an indepth understanding and domain from different interpretations are the center of the construction of this important concept of differential calculus. This article ends with the presentation of a validated design for the understanding of the derivative, as a viable tool in the processes of understanding its local aspect, with the purpose of proposing reflective opportunities that will aim to generate classroom sequences for the teaching and learning of differential calculus for first year university students.

\section{Historical and epistemological analysis of the derivative from a local perspective}

This research accepts the theoretical premises of theory and practical thinking of Sierpinska (2000) thinking modes. In this sense it is fundamental to note the mathematical notions as knowledge marked by abrupt changes in its 
understanding, through its historic development. The advance of more than two hundred years of differential calculus, contributes relevant milestones to analyze the epistemological route of the local aspect of the derivative, allowing to highlight the obstacles that had to be overcome by mathematicians and scholars of different ages, to achieve an understanding of the concept. In this sense three historic moments are described, to show a summary of the progress from the different ways of understanding the derivative in its local aspect.

A first moment or origin of the derivative, corresponds to the period between the old ages and the XVI Century, in which the derivative is considered as a tool to solve problems, such as the instant speed of a mobile or determine tangents of a curve (graphic of a function) at a given point. The ancient greeks conceived these notions from a static and naturally geometric point of view (use of ruler and compass). For them, movement was impossible, space and time infinitely divisible, avoiding infinite processes, this is, infinitely small amounts (Boyer, 1959).

A second moment takes place during centuries XVI and XVII, with the rise of ideas such as the application of symbolic algebra for the study of geometrical problems, the association of curves and equations in a system of coordinates. At this moment, it is important to highlight that the analytical geometry facilitated the advance of Mathematics in relation to the use of the derivative. In the latter we can highlight the methods of Fermat and Roberval, which became general algorithmic methods, since at the time there were no systematic resolution methods. It was not until the end of the XVII century with the work of Newton (1642-1727) and Leibniz (1646-1716), that procedures were developed to solve the tracing of the straight tangent line to a curve, the instant speed of bodies in movement, the calculation of maximum and minimum in a curve, etc., giving birth to what is currently known as differential and integral calculus (Steward, 2007).

The dominant mathematical ideas of this time conflicted with the concept of limit, because there was no rigorous proof of the infinitely small, due to the intuitive use of the notions of continuity, convergence and failure to provide a justification for a quotient that approximates to cero and that would give an interpretation to the local aspect of the derivative, other than through limits.

A third moment, from centuries XVIII to XIX, established the functional nature of the derivative, through the differential aspect of a function in a point that allows to approximate the function through a polynomial equal or smaller to one. In this time $\frac{d y}{d x}$ was no longer thought of as an infinitesimal proportion. This is what Lagrange called the false idea of the infinitely small (Grabiner, 1983). Augustin-Louis Cauchy gave birth -starting from a precise definition of limit- to the XIX century theories of convergence, continuity, derivative and integral.

In summary, these three historical moments of the local aspect of the derivative identify three mathematical aspects of interest: the derivative as the slope, the derivative as the limit and the derivative as the best approximation, being also possible to distinguish and acknowledge the limit and tangency as key notions to define the local aspect of the derivative.

From the point of view of Bachelard (2000), the straight tangent line goes from being an object of study to measure space, to an object of study for measuring change. In this sense, Montoya Delgadillo and Vivier (2015), show 
evidence that the conception of the straight tangent line is an epistemological obstacle for the understanding of the derivative in its local aspect and the concept of limit as a geometrical obstacle, in the sense that infinitely small quantities are an abstraction in the geometric context of areas computation.

\section{Theoretical framework}

The Sierpinska (2000) thinking modes were developed in linear algebra, with the purpose of addressing the fundamental problem of overcoming the epistemological obstacles of this fragment of Mathematics, and to clarify theoretical thinking. In the case of this research, this framework provides the basal theoretical elements on which we support a variation, to raise -ways of thinking the derivative in the local aspect- with the purpose of inquiring different forms in which students think, understand and relate mathematical concepts involved in the understanding of the derivative from a local perspective.

\section{Sierpinska Thinking Modes}

Sierpinska (2000), proposes two reasoning categories of students of linear algebra, a practical thought and a theoretical thought, as a duality in tension, from where the need arose to clarify theoretical thought. For this, she distinguishes three thinking modes in linear algebra, that correspond to three different meanings, which interact among them through articulators1 to promote a deep understanding of mathematical concepts of linear algebra. The modes that she describes have the purpose of overcoming the epistemological obstacle that emerges as the result of two dogmatic opposing views in the epistemological historic development of linear algebra, this is, on one hand the rejection of numbers within geometry and on the other the view that geometrical intuition can be taken to a purely arithmetic domain. To overcome this obstacle, Sierpinska identifies the coexistence of three thinking modes, defined as follows:

Synthetic-Geometric Mode (SG): The objects are given to be described directly by the mind, is the direct image between the subject and the object and considers language of geometrical figures, points, lines and planes, as well as its conventional graphic representations.

Analytic-Arithmetic Mode (AA): The algebraic search is used for the representation of the object, what are given through numeric relations in the Cartesian system.

Analytic-Structural Mode (AE): The mathematical object is a structural whole that can be identified starting from a group of properties or axioms that describe it.

Each of these Modes allows for a different view of the mathematical object in linear algebra, a fact that theory proposes as essential to achieve superior levels of abstraction, which are achieved through the interaction of the three modes. However, these are not stages in the development of thought of linear algebra, but rather are understood as different and equally useful modes when they interact in a specific task (Parraguez, 2012).

This thinking modes for linear algebra now support, from the historic and epistemological study of the derivative, an extension of this theoretical referent 
towards differential calculus, which gave place to ways of thinking the derivative in its local aspect.

\section{Modes of thinking the derivative from a local perspective}

This research presents a variety as an extension of the thinking modes proposed by Sierpinska to the domain of the derivative, to describe its understanding in the local aspect, assuming as the fundamental theoretical problem, the overcoming of the epistemological obstacle of the derivative (This is, on one hand, the incorporation of elements of the geometric domain to measure change and on the other that the abstraction of a geometrical nature of the infinitely small can be taken to a purely algebraic domain of the limit), through the notion of limit and the notion of straight tangent line, which support access paths to the derivative at a local level, in agreement with the modes proposed by Sierpinska (2000), summarized in Figure 1.

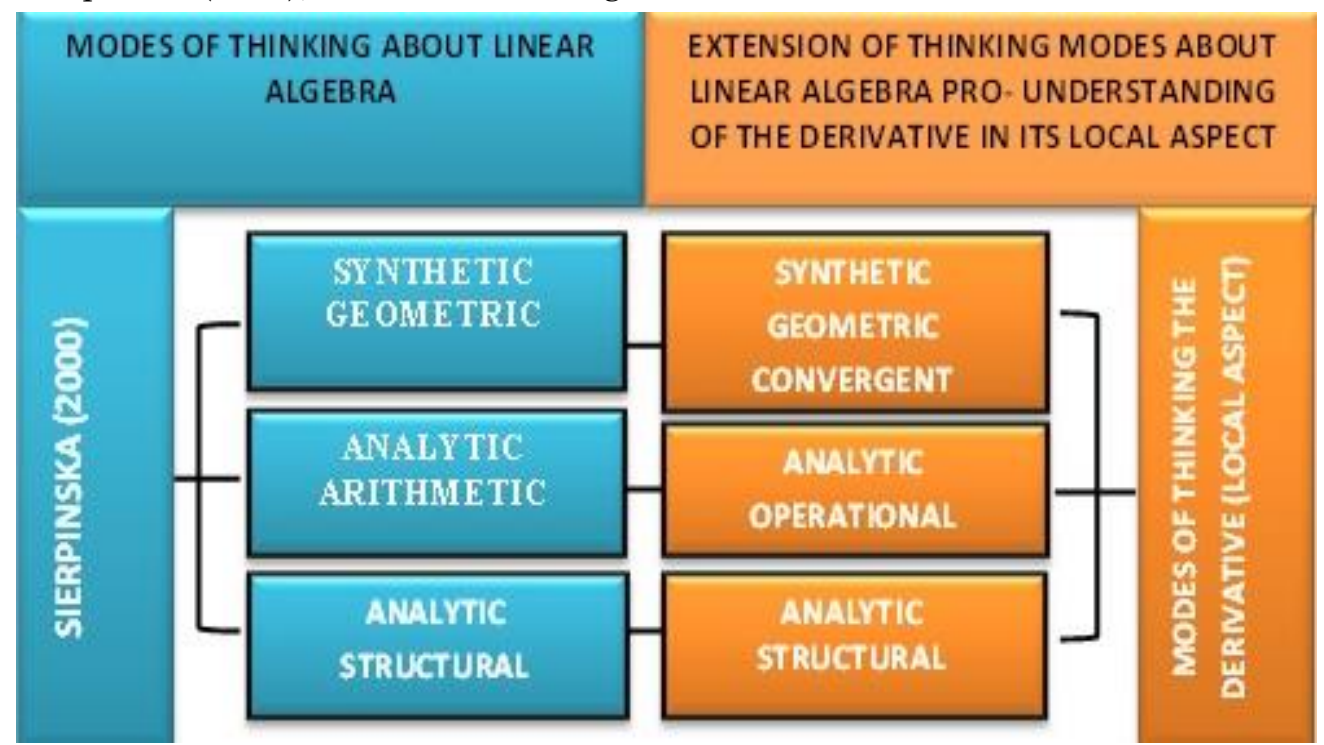

Figure 1 Characterization modes of thinking the local aspect of the derivative in relation to the Thinking Modes of Sierpinska.

The geometrical conception of the derivative is highlighted in the first historical and epistemological moment, delimiting the practical thinking mode for the derivative. The other two modes $-\mathrm{AA}$ and $\mathrm{AE}$ - agree with the theoretical thought of the derivative, however, it will be made clear, determining its analytical relationship as the limit of the slopes of the secant lines, losing the arithmetical character mentioned in the second historical moment, but highlighting the operational character of the derivative, in its local aspect. In the third moment, a local property of the derivative is clarified from the understanding of the best linear approximation to the curve, considering the differential calculus context, in agreement with the intuitive treatment of the limit. We will next present the three modes of understanding the derivative from a local perspective.

Presentation of the Synthetic-Geometrical-Convergent Mode of the Derivative from a local perspective (SGC) 
The geometric interpretation of the derivative of a function from a local perspective is supported on the proximity of the tangential point and to describe a synthetic and geometric mode we resorted to the definition performed by D'Alembert (1717 - 1783), this is, the slope of the tangent line as the limit of the slopes of the secant lines.

From the mathematical point of view the convergence is supported in the idea of straight lines, but thought as group limits, because the straight tangent line is the limit of the secant lines that come from the left and the right, and the limit line of the secants from the right coincides with the limit line of the secants from the left and this limit is the tangent line. This consolidates convergence, considered in this mode of understanding of the derivative as forming part of the Synthetic-Geometric-Convergent mode of the derivative locally (SGC), so the continuous real functions $C$ and a given point $P$ on its graphic whose movement of the secant line $P Q i$ coming to this limit position, that is when $Q i$ is next to $P$ will be represented by the slope of the tangent line in $P$ (Figure 2).

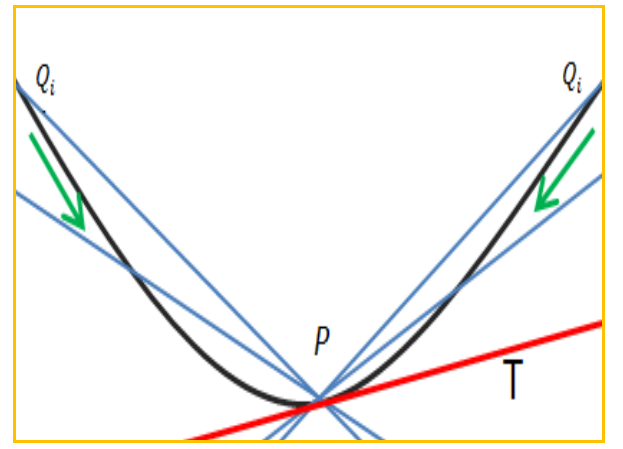

Figure 2 SGC Mode, for the understanding of the derivative locally.

The SGC mode agrees in the sense with Zimmermann and Cunningham (1991), with the tangent line of the graphic of a function in each point, and the tangent line as the fundamental notion to achieve the direct and observable image of the concept of the derivative of a point.

\section{Presentation of the Analytic-Operational Mode of the concept of Derivative from a local perspective (AO)}

This mode is presented as the tangent line with multiple secant lines, which have progressively smaller distances between the two points in the graphic of the function, (Figure 3). Each secant line is associated to a slope and that slope depends from $\mathrm{h}$ (h represents a small quantity that disappears when $Q i$ comes close to $P$ ) in the given point $P$. Slopes converge both from the right and left. When they take the limit of the slopes of secant lines of this progression the slope of the tangent line is achieved.

With this idea we can define: The derivative of a f function defined in its domain and continuous, as the slope of the tangent line of $f$ in the $P$ point: $\left(\mathrm{x}_{0}, f\left(\mathrm{x}_{0}\right)\right)$. The slope of the secant line $\left(m_{g}\right)$ that goes through points;




With this purpose, the relatively small number $\mathrm{h}$ represents an also small change in $x_{0}$, and the derivative of $\mathrm{f}$ in a given point, which is the limit of the value of the difference quotient, as long as the slopes of the secant lines converge to the tangent line slopes, this is $\mathrm{f}^{\prime}\left(\mathrm{x}_{0}\right)=\lim _{\mathrm{h} \rightarrow 0} \frac{\left.\mathrm{f} \mathrm{x}_{0}+\mathrm{h}\right]-\mathrm{f}\left(\mathrm{x}_{0}\right)}{\mathrm{h}}$. If this limit exists, then we can say that the derivative of $\mathrm{f}$ in point $P$ is $\mathrm{f}^{\prime}\left(\mathrm{x}_{0}\right)$. This limit formalizes the intuitive idea of approximation, and the function approximates to the limit, while the variable approximates to an " $\mathrm{x}_{0}$ " operation on the differences that is not purely arithmetical. Then, the mode AA defined by Sierpinska must be reinterpreted as the Analytic-Operational (AO) to attend to the understanding of the derivative from the local aspect.

\section{Presentation of the Analytic-Structural Mode of the concept of Derivative from a local perspective (AE)}

To interpret the concept of the derivative in its structural form we resort to inherent properties of the concept or its own axioms that will allow to explain it as a unique object within Mathematics, this is the derivative as the best linear approximation of the curve in point P. From this, a real differentiable real function $f$ of real variable can be expressed in the following way: $f(x)=f\left(x_{0}\right)+f^{\prime \prime}\left(x_{0}\right)\left(x-x_{0}\right)+o(x)$, where $y=f(x)$ and $\left(\mathrm{x}_{0}, \mathrm{f}\left(\mathrm{x}_{0}\right)\right)$ is the point and $o(x)$, is a function that represents error, through the $\lim _{x \rightarrow 0} \frac{O(x)}{x}=0$, (Lang, 1972), and the derivative is a linear transformation (Poole, 2014).

Figure 3 presents a summary of the three modes of thinking the derivative from the local perspective.

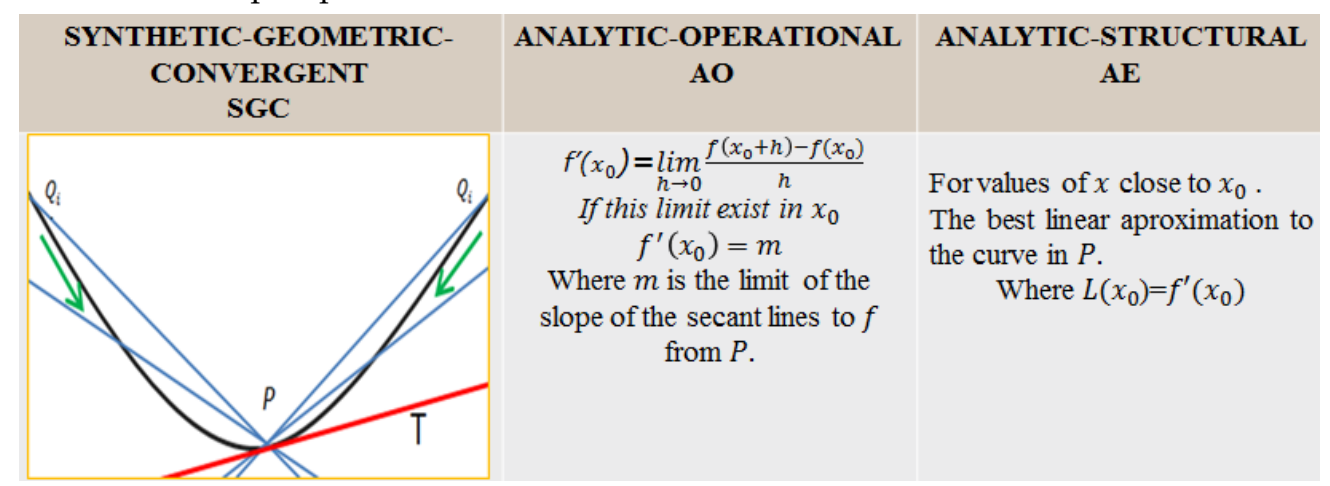

Figure 3 Description of the SGC, AO and AE modes of the concept of derivative from its local aspect.

Now that we have presented and epistemologically supported the thinking modes of the derivative from the local aspect, it is our interest now to clarify its articulating elements, which are described in the following section:

\section{Hypothetical Articulators for the thinking modes of the derivative in its local aspect}

In Figure 4, we show the diagram related to the search of the articulating elements. For this it is necessary to consider the question: What mathematical elements articulate the $\mathrm{SGC}, \mathrm{AO}$ and $\mathrm{AE}$ modes of the concept of the derivative in its local aspect? 
In general the underlying hypothesis in the characterization of observable elements to understand the derivative in its local aspects in Figure 3, is that reasoning is described through the interaction of practical and theoretical thought, expressed in the ability of the student to interact between the SGC, AO and $\mathrm{AE}$ modes of the derivative, so that the data collecting techniques allow us to identify and describe such elements that promote this movement articulators-a fundamental aspect for the development of what this study seeks to communicate.

Specifically, based on the historic and epistemological study of the derivative in its local aspect, a proposal of articulating elements among these three modes (SGC, $\mathrm{AO}$ and $\mathrm{AE}$ ) is presented.

$\mathrm{H} 1$ : The right-angled triangle in the coordinate system (formed by the secant line and horizontal line), as an articulator between the AO and SGC modes.

H2: The slope of the tangent line in a curve point, as an articulator between the $\mathrm{AO}$ and $\mathrm{AE}$ modes.

H3: The equation of the tangent line, as an articulator between the SGC and $\mathrm{AE}$ modes.

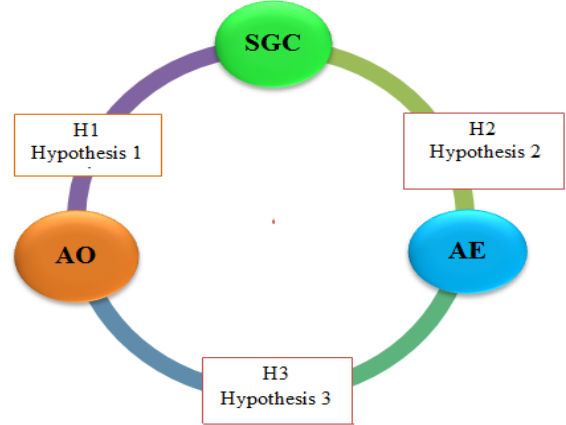

Figure 4 Relation of hypothetical articulators with thinking modes of the derivative in its local aspect.

\section{Method}

The objective of inquiring in the elements that facilitate deep understanding of the derivative in its local aspect, circumscribes this research to the hermeneutic paradigm, with an emphasis on interpretation and description of information, centered on the understanding of the local aspect of the derivative, through a qualitative, non-general study (Stake, 2010), materialized in a case study with the purpose of performing an in-depth investigation of the articulators of the thinking modes of the derivative from a local perspective, and in search of empirical evidence to validate, refine or refute the proposed articulating elements in Figure 4. For this purpose, we considered a first moment, with two groups of students, Case 1 and Case 2, with the technique of questionnaire application. A second moment had to be implemented later, to complement with a Case 3 formed by teachers (with a doctorate in Mathematics), applying a semi-structured interview, with the objective of inquiring and specifying the articulating elements among SGC, AO and AE. 


\section{Participants}

To show evidence of the deep understanding of the derivative from a local perspective, we selected two groups of first year students (18-19 years old) in a Chilean university, who volunteered to address techniques of data collection so the researchers could interpret their observable arguments from the three proposed modes -SGC, AO and AE-.

Case 1: Ten Mathematics Education students that are taking the Differential Calculus class at the time of the study, labeled as PM1..., PM10.

Case 2: Three Mathematics students that have taken Differential Calculus during the semester prior to the data collection, labeled as LM11, LM12 and LM13.

Since the analyzed data of Cases 1 and 2 was insufficient to describe with precision the articulating elements between the proposed modes in Figure 4, it was necessary to add another case to complement the source of data collection, formed by Differential Calculus teachers, with the purpose of comparing the gathered data with the hypothetical proposed articulators.

Case 3: Three Ph.D. in Mathematics, researchers with great experience in the university teaching field, labeled as DM14, DM15 and DM16.

DM14: Ph.D. in Mathematics in Mathematics assigned to the line of research of Differential Geometry Control Theory, Lie Groups, Lie algebras and its Applications Semigroups, Optimality.

DM15: Ph.D. in Mathematics in Mathematics assigned to the line of research in Geometry Control Theory and Sub-Riemannian geometry.

DM16: Ph.D. in Mathematics in Mathematics assigned to the line of research of Dynamic Systems and Differentiable Ergodic Theory.

\section{Implementation and questionnaire application}

During the first moment a four-question questionnaire was designed and applied to Cases 1 and 2. The questions were based and validated through the judgement of experts, and submitted to several co-evaluations and adjustments.

Each informant received the first question in a separate sheet from the rest of the questionnaire, where the answer was hand written on the paper and submitted once completed. Later, they received the remaining three questions. Students worked on the answers on a separate sheet of paper, with 90 to 120 minutes to answer. During the application of the questionnaire we answered questions regarding the understanding of the instructions. The answers of the whole instrument were later digitalized so we could analyze them later.

\section{Implementation and interview application}

During the second moment, a semi-structured interview was implemented with Case 3. This methodological technique (Redon and Angulo, 2017) was considered in this occasion to inquire in-depth about articulating elements through an interpersonal and flexible dialogue. The script was developed in a conversation format, so the interviewee could express her points of view with the possibility of clarifying any doubts during the process, ensuring answers that would better serve the purpose of the research. The goal of applying this technique is to obtain information as detailed as possible about the articulators 
between the SGC, $\mathrm{AO}$ and $\mathrm{AE}$ modes. Therefore, the informant was presented with three cards, as shown in Figure 5, labeled as CARDS 1, 2 and 3 of the derivative (that agree with the proposed model in Figure 3. This consideration is because we need to facilitate a reflection from the interviewee).
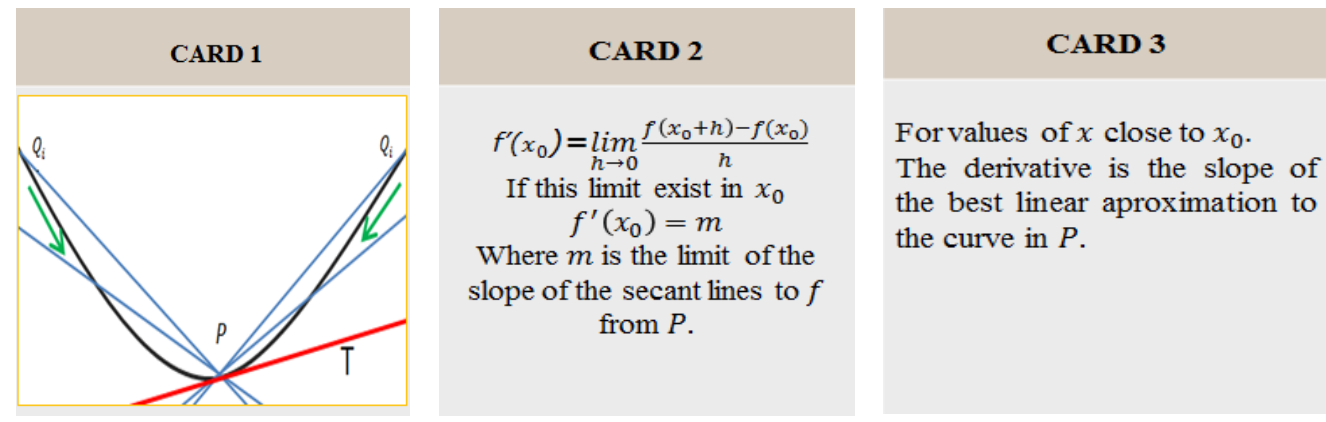

Figure 5 Description of the cards used in the interviews for Case 3.

The interview is performed with no time limit, taking photos of the written reproductions and recording all the conversations that were later transcribed to be analyzed by the researchers.

\section{Analysis of the questions of the questionnaire of the thinking modes of the derivative from a local perspective}

A previous analysis by question was considered from the described modes (SGC, AO and $\mathrm{AE}$ ), with the purpose of contrasting it to the response analysis of Case 1 and Case 2. We must note that the answers gather elements of practical and theoretical thought of the informant, as he refers to algebraic, analytical, geometrical or structural matters, that he gets in tune with the purposes of the design of the instrument, this is to obtain data that accounts for the mathematical elements that the student sets into action when moving from one thinking mode to another and with this also detect possible difficulties in the articulation.

We will describe the questions in the questionnaire, in which we specify the research intention of each question, through coding that helped us to summarize the information.

SGC: Indicates that the student places her answer in the SGC mode

AO: Indicates that the student places his answer in the AO mode

AE: Indicates that the student places her answer in the AE mode

$\mathrm{SGC} \rightarrow \mathrm{AO}$ : Indicates that the student initially places his answer in the SGC mode and transitions to the AO mode.

SGC $\leftrightarrow$ AO: Indicates that the student initially places her answer in the SGC mode and transitions to the AO mode and vice versa.

Question 1 (Open question) 
How would you explain, the local aspect of the derivative to a High School student?

The objective of this question is to inquire the thinking mode of the derivative that students prioritize. Table 1 shows the possible interpretations or answers.

Table 1 Possible interpretation from the thinking modes for the derivative in its local aspect.

Possible observable arguments of the informant
Interpretation from the

thinking modes of the derivative in its local aspect

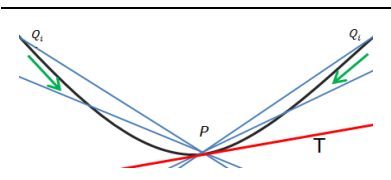

SGC

The $\mathrm{T}$ slope in the $\mathrm{P}$ point.

The limit of the average exchange rate. Instant speed.The limit of the average speed.The limit of the slope of the secant lines that go through a specific point.

The best approximation of the curve from a local perspective in a specific point.The function that behaves as a line in a specific point.

$\mathrm{AE}$

Question 2 Let the function be $\mathrm{f}(\mathrm{x})=\mathrm{x}^{2}$, the table shows the resulting values of the quotient $\frac{\mathrm{f}[1]-\mathrm{f}(\mathrm{x})}{1-\mathrm{x}}$ that are the slopes of the secant lines when $\mathrm{x}$ approximates to 1 .

\begin{tabular}{|c|c|c|c|c|c|c|c|}
\hline$x$ & 0.59 & 0.9 & 0.99 & 0.999 & 1.001 & 1.01 & 1.1 \\
\hline$\frac{f(1)-f(x)}{1-x}$ & 1.59 & 1.9 & 1.99 & 1.999 & 2.001 & 2.01 & 2.1 \\
\hline
\end{tabular}

Make comments and explain the information in the table, in relation to the derivative of the function and the tangent line at the $(1,1)$ point. Justify your observations.

This intention of this question is that the student situates himself in any of the three modes and transitions to the others: From AO $\rightarrow$ SGC, from SGC $\rightarrow$ $\mathrm{AE}$ and $\mathrm{AE} \rightarrow \mathrm{AO}$. Table 2 shows the possible interpretations or answers.

Table 2 Possible arguments and interpretations from the thinking modes of the derivative in its local aspect.

Possible observable arguments of the informant

Interpretation from the thinking modes of the derivative in its local 


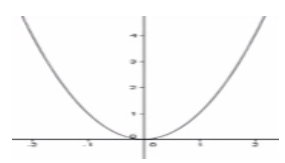

SGC

Calculate the limit of the slopes of the secant lines in the point, and indicate that $\mathrm{f}^{t}(1)$ is the slope of the tangent $\mathrm{AO}$ line.

\footnotetext{
In its account the student writes that the best slope to approximate the curve in the point is between the following values: $\quad \mathrm{x}=0,999$ and $\mathrm{x}=1,001$, $\mathrm{AE}$

$L(x)=f(1)+f^{x}(1)(x-1)$

If $\lim _{x \rightarrow 1} \frac{f(1)-f(x)}{1-x}=2$, exists in $x=1$, then there is a tangent line of slope $m=2$. The difference quotient, $\frac{f(1)-f(x)}{1-x}=m$ is a slope.

$$
\mathrm{AO} \rightarrow \mathrm{SGC}
$$

If $\lim _{z \rightarrow 1} \frac{f(1)-f(x)}{1-x}=2$, then, $m=2$, is the slope of the line that better approximates to the function.

$\mathrm{AO} \rightarrow \mathrm{AE}$

In $x=1_{x}$ there is a tangent line to the curve, $L(x)=2 x-1$, so that: $L(x) \& f(x)$ in $x=1$.

$\mathrm{SGC} \rightarrow \mathrm{AE}$
}

Question 3 Suppose that $f$ is a function, so that: $\lim _{\mathrm{h} \rightarrow 0} \frac{\mathrm{f}(\mathrm{2}+\mathrm{h})-\mathrm{f}(2)}{\mathrm{h}-2}=0$. $(2, f(2))$ ? How is the behavior of the graphic of the function, next to

b) What are the characteristics of the best approximation to the function in $(2, f(2))$ ?

This question has the purpose of inquiring if the student understands the concept of differentiality in a point $(\mathrm{a}, f(\mathrm{a})) \in \mathbb{R}^{2}$. Table 3 shows the posible interpretations or answers.

Table 3 Possible arguments and interpretation from the thinking modes of the derivative in its local aspect.

\section{Possible observable arguments of the informant}



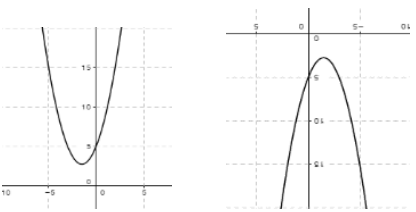

Or a

turning

point

SGC

Accounts for the limit that corresponds to the derivative of the function evaluated in $x=2$ and corresponds to a $\mathrm{AO}$ maximum or a minimum.

\begin{tabular}{|c|c|}
\hline $\begin{array}{l}\text { Argues that if the slope is cero in } \mathrm{x}=2 \text {, surrounding that } \\
\text { point there is a horizontal line that is its best local } \\
\text { approximation. } \mathrm{L}(\mathrm{x}) \approx \mathrm{f}(\mathrm{x}) \mathrm{enx}=2 \text {. }\end{array}$ & $\mathrm{AE}$ \\
\hline $\begin{array}{l}\frac{\mathrm{f}(\mathrm{x})-\mathrm{f}(2)}{\mathrm{x}-2}=\frac{\mathrm{f}(2+\mathrm{h})-\mathrm{f}(2)}{\mathrm{h}} \text {, is the variation rate, that indicates } \\
\text { approximation of the function to cero. }\end{array}$ & $\mathrm{AO} \rightarrow \mathrm{SGC}$ \\
\hline $\begin{array}{l}\text { If the limit is cero then the slope of the tangent line is } \\
\text { cero, therefore its best local approximation is a horizontal } \\
\text { line. }\end{array}$ & $\mathrm{AO} \rightarrow \mathrm{AE}$ \\
\hline $\begin{array}{l}\text { In the proximity } \\
\text { of point }(2, \mathrm{f}(2))\end{array}$ & $\mathrm{SGC} \rightarrow \mathrm{AE}$ \\
\hline
\end{tabular}

\section{Question 4}

If we consider that the law of movement of a point is $y(t)=2 t^{2}+3 t+5$, which is the median speed of the point between $t=2 \mathrm{sec}$ and $t=5 \mathrm{sec}$ ? Which is the speed in $t=3 \mathrm{sec}$ ? Justify your answer.

This question intends to observe if the student understands the local aspect of the derivative, and the possible transitions between its modes. Table 4 shows possible interpretations or answers.

Table 4 Possible arguments and interpretation from the thinking modes of the derivative in its local aspect.

\section{Possible observable arguments of the informant}

Interpretation from the thinking modes of the derivative in its local aspect 
$L(t)=f\left(t_{0}\right)+f^{0}\left(t_{0}\right)\left(t-t_{0}\right)$

$\mathrm{L}(\mathrm{t}) \approx \mathrm{f}(\mathrm{t})$, in the vecinities of $\mathrm{t}_{0}$

In $\mathrm{t}=3_{s} \mathrm{~L}(\mathrm{t})=15 \mathrm{t}-13 \approx \mathrm{y}(\mathrm{t})$

If $\left(\mathrm{a}_{\mathrm{v}} \mathrm{f}(\mathrm{a})\right)$ ) and $(\mathrm{a}+\Delta \mathrm{x}, \mathrm{f}(\mathrm{a}+\Delta \mathrm{x}))$, are two points write: the exchange rate or exchange ratio: $\frac{\Delta y}{\Delta x}$.

Median speed corresponds to calculate:

$v_{m}=\frac{y(5)-y(2)}{5-2}=\frac{70-19}{a}=\frac{51}{a}$, then the median speed of the $\mathrm{AO} \rightarrow \mathrm{SGC}$ point between $\mathrm{t}=1$ and $\mathrm{t}=5$ is $\mathrm{v}_{\mathrm{m}}=\frac{51}{\mathrm{a}}\left(\frac{\mathrm{m}}{\mathrm{gec}}\right)$.

$\lim _{\Delta x \rightarrow 0} \frac{\Delta y}{\Delta x}=f^{\prime}(a)=m$, where $m$ is the slope of the tangent line.

In $\mathrm{t}=3$, there is a line that is the best linear approximation of the $y(t)$ graphic.

\section{Results}

To organize and describe the work performed by the students that compose Cases 1 and 2 of this study, we have arranged the information in Table 5 , that shows the obtained results of the questionnaire in a question by question format.

Table 5 Interpretation of the data from the thinking modes of the derivative in its local aspect: Case 1 and Case 2.

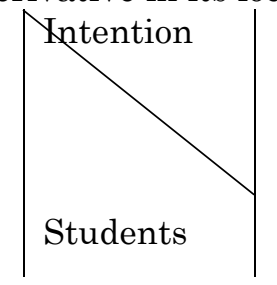

Interpretation of the observable arguments from students

$\begin{array}{llll}\text { Question } 1 & \text { Question } 2 & \text { Question } 3 & \text { Question } 4\end{array}$




\begin{tabular}{|c|c|c|c|c|c|}
\hline & PM1 & $\mathrm{SGC}$ & $\mathrm{AO} \rightarrow \mathrm{SGC}$ & $\mathrm{AO} \rightarrow \mathrm{SGC}$ & $\mathrm{AO}$ \\
\hline & PM2 & $\mathrm{SGC}$ & SGC & No answer & $\mathrm{AO}$ \\
\hline & PM3 & SGC and AO & $\mathrm{AO} \rightarrow \mathrm{SGC}$ & Doesn't know & $\mathrm{AO}$ \\
\hline & PM4 & SGC and AO & $\mathrm{SGC}$ & No answer & $\mathrm{AO}$ \\
\hline & PM5 & $\mathrm{AO}$ & $\mathrm{SGC} \rightarrow \mathrm{AO}$ & Doesn't know & No answer \\
\hline & PM6 & $\mathrm{AO}$ & $\mathrm{AO} \rightarrow \mathrm{SGC}$ & No answer & $\begin{array}{l}\text { Doesn't } \\
\text { know }\end{array}$ \\
\hline & PM7 & $\mathrm{AO}$ & $\mathrm{SGC} \rightarrow \mathrm{AO}$ & No answer & $\mathrm{AO}$ \\
\hline & PM8 & SGC and AO & $\mathrm{AO} \rightarrow \mathrm{SGC}$ & No answer & No answer \\
\hline & PM9 & SGC and AO & No answer & No answer & $\begin{array}{l}\text { Doesn't } \\
\text { know }\end{array}$ \\
\hline$\neg$ & PM10 & SGC and AO & No answer & $\mathrm{SGC} \rightarrow \mathrm{AO}$ & $\mathrm{AO}$ \\
\hline & LM11 & SGC and AO & $\mathrm{AO} \rightarrow \mathrm{SGC}$ & $\mathrm{A} \rightarrow \mathrm{AE}$ & $\mathrm{AO}$ \\
\hline & LM12 & SGC and AO & $\mathrm{AO} \rightarrow \mathrm{SGC}$ & $\mathrm{AO} \rightarrow \mathrm{AE}$ & $\mathrm{AO}$ \\
\hline $\begin{array}{l}N \\
0 \\
0 \\
0 \\
\sigma \\
\sigma\end{array}$ & LM13 & SGC and AO & $\mathrm{AO} \rightarrow \mathrm{SGC}$ & $\mathrm{SGC} \rightarrow \mathrm{AO}$ & $\mathrm{AO}$ \\
\hline
\end{tabular}

From Table 5, we have selected episodes per question that are highlighted in blue, since they show: (1) how students work from the position of each one of the modes, (2) how they transition from one mode to the other and (3) the difficulties to articulate the three modes.

Later we performed an account per question that shows a general vision of the analysis of the answers given by the students, continuing with the particulars of each one of the selected episodes. 


\section{Question 1}

None of the students from Cases 1 and 2 considers the AE mode of the derivative in their arguments. Students of Case 2 place themselves in the SGC and AO modes. The student labeled PM4 situated himself in the AO mode to respond, later in the SGC, through the definition -which was the most recurring given by students- (Figure 6), and then back to the AO mode.

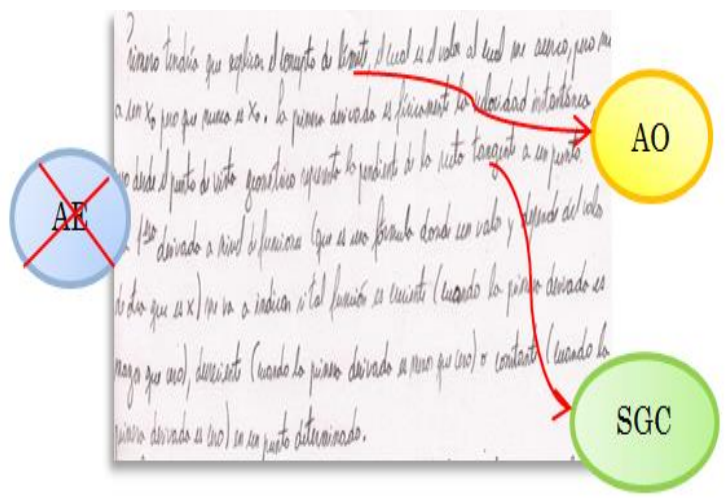

First, I would have to explain the concept of limit, which is the value I come close to, but much to a $\mathrm{s}_{\mathrm{s}}$ that, is however, never $\mathbb{s}_{0}$. The first derivative is physically the instant speed.

From the geometrical standpoint it represents the slope of the tangent line to a point.

The first derivative at the functions level (which is a formula where a " $y$ " value depends on other that is " $\mathrm{x}$ ") will indicate me if said function is increasing (when the first derivative is greater than cero), decreasing (when the first derivative is less than cero), or constant (when the first derivative is cero) at a given point.

Figure 6 Response of PM4. He shows that he situated himself in the SGC and $\mathrm{AO}$ modes.

Another student, PM8, in the last part of his answer (Figure 7) does not refer to the derivative from a local perspective, but to one use of the derivative.

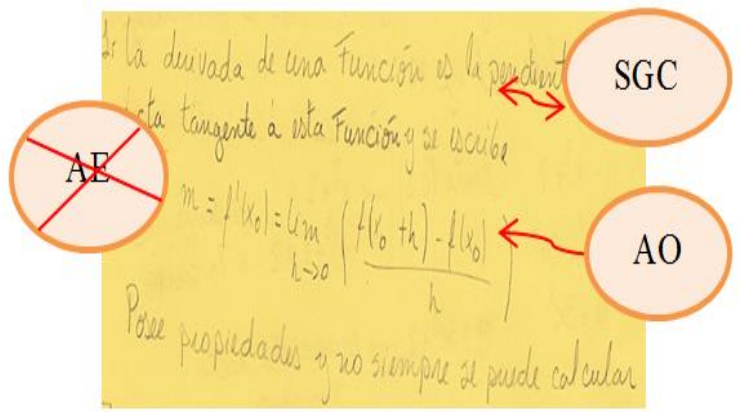

The derivative of a function is the slope of the line that is tangent to the function and is written in the following way.

It has properties and not always can be calculated.

Figure 7 Answer of PM8. She shows to situate herself in the SGC and AO modes.

This argument shows that PM8 student initially thinks and visualizes the SGC mode, following with the AO mode, to write a definition. However, there are no indicators of elements that consider the structural mode.

\section{Question 2}


Data shows that students have difficulties to respond when they have situated themselves in the SGC mode first. Students PM3, PM6 correctly analyze the information given in the question, indicating the relation of the limit with the data provided in the table, first situated in the AO mode. However, PM5, situated in the SGC mode, shows an attempt to transition towards AO, but his argument is not enough to explain how he relates both. PM2 and PM4 try to argue their answer in the SGC with no success. Another student, PM7, situates himself in the SGC mode, but his argument is confusing in relation to the slope that he calls image, when he names the two (2), this is interpreted as a mistaken argument regarding the slope (Figure 8) and there is no clear evidence of an articulator, however, there is evidence that he changes modes.



Well, it can be observed when $\mathrm{x}$ is farther than 1 by the right. Its image moves away from 2 by its right too and therefore the points that correspond to the secant line come closer to the function $f(x)=x^{2}$.

Figure 8 Informant PM7, shows his resolution in the $\mathrm{SGC} \rightarrow \mathrm{AO}$ mode.

Student LM11 (Figure 9), represents the recurring answer of students, acknowledging the connection between the limit of the given quotient and the slope of the tangent line in the point. Her argument is in the AO mode, and it is evident that there is a change of thinking modes, however, from the evidence we cannot identify the articulator between the AO and SGC modes.



It is a function that does not present continuity, and, I try to arrive.

Figure 9 Student LM11, understanding from the AO $\rightarrow$ SGC modes

\section{Question 3}

This question presented problems for most of the students, because they answer situated in the AO mode, identifying point (2, f (2)) as student LM12 shows (Figure 10), however PM12 gives more argument for his answer, specifying that the tangent line is a horizontal line in the point, but does not declare that it can be the best approximation. There is evidence in his argument of a transition to the SGC mode, however, there is no evidence of the mathematical element that allows him to articulate AO with SGC. 


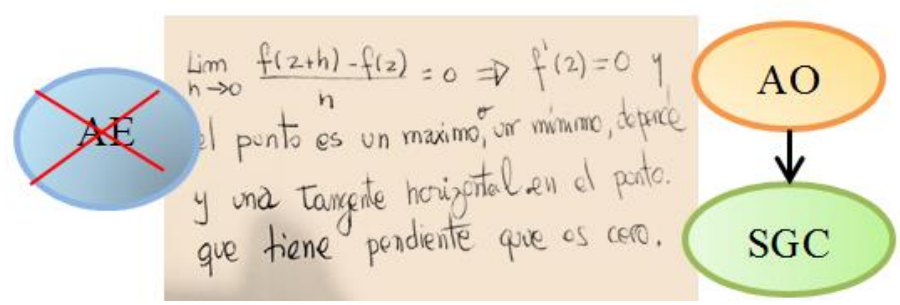

The point is a maximum, a minimum, it depends, and a horizontal tangent in the point that has a slope equal to cero.

Figure 10 Student LM12, understanding from the AO $\rightarrow$ SGC modes.

\section{Question 4}

Students in general treat instant speed in the same way than median speed, a representative example of answers is shown by student PM7 (Figure 11), whom, situated in the $\mathrm{AO}$ mode cannot transition towards the other modes. However, he adds a different argument than median speed, when he relates it to the average speed.

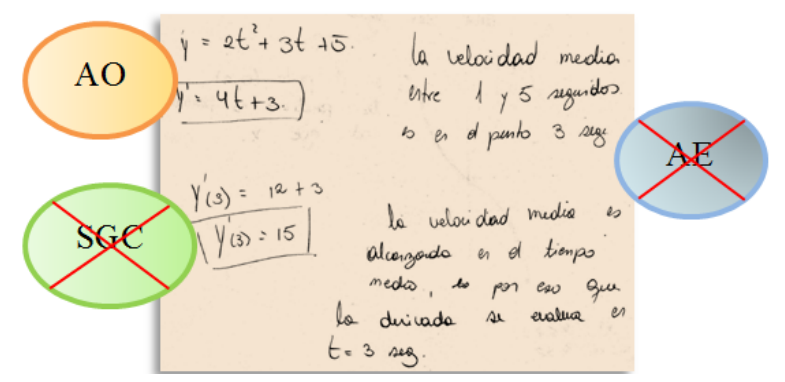

Median speed between 1 and 5 seconds is the 3 sec point.

Median speed is achieved in average time, that is why the derivative is evaluated in $t=3 \mathrm{sec}$.

Figure $11 \mathrm{PM} 7$, in AO confuses median speed with instant speed.

\section{Interview analysis}

What follows are textual fragments of some interviews, that allowed to clearly identify the articulating elements between SGC, AO and AE modes.

\section{Identifying the articulator between SGC and AO}

Regarding the articulating element between the SGC and AO modes, DM14, when manipulating cards 1 and 2, situated himself first in the SGC mode, however his reflection is centered in a relationship of equivalency that will allow him to transition to AO mode, identifying the right-angle triangle, as a bi-directional articulator (Figure 12), formed by two points in the graphic of the function. However, DM14, proposes another articulator -the shaded area(Figure 12). The following are fragments of the interview in which DM14 mentions these two articulators.

[20DM14] "I am thinking about a way to transition from Card 1 (SGC), and look for elements that allow the student to transition to Card 2 (AO). What I want to see is the mathematical consistency of saying that there is a relationship of equivalence of the line with the slope, [pause]...I could visualize it through a rectangle. Perfect, this triangle is perfect, because first you

SGC

$\downarrow$


explain the triangle to the student, the tangent line and with that, the guy [student] understands.

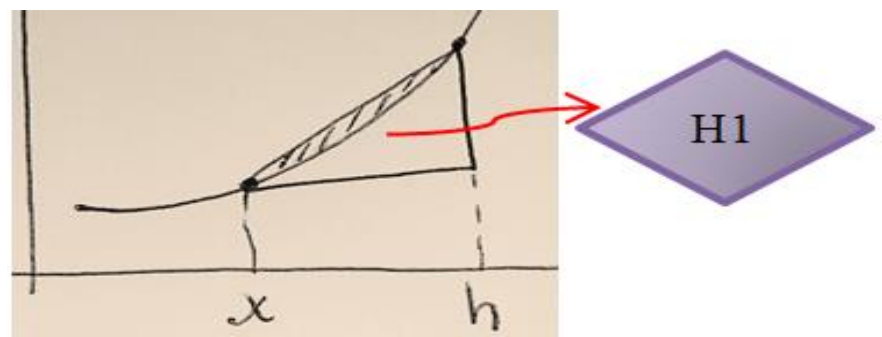

Figure 12 Graphic record of DM14, in relation to the articulator for the SGC mode to the $\mathrm{AO}$ mode.

The DM15 informant, also thinks about the triangle, but she initiates her account positioned from the AO mode, specifically when referring first to the quotient and then thinks of the triangle. In Figure 13, the articulator between SGC and AO modes is shown, and DM15 shows that is bi-directional and describes the quotient through the triangle, being the variation rate the intuitive access to the concept of limit -and it is precisely the triangle that allowed DM15 to notice the limit-. His account describes what he did in the diagram.

[11DM15] First you can fix the $f(x)$ of point P and can say that $f(x+h)$ is the end of the triangle, in connection with point $Q$, or it can be looking at any point of the other side, to the left or right of $\mathrm{P}$. In relation to the quotient, you have a triangle, with that we are thinking about the limit, with relation to the quotient, you have a triangle and with that I relate to the value of $h$ that is what defines the side of the triangle.
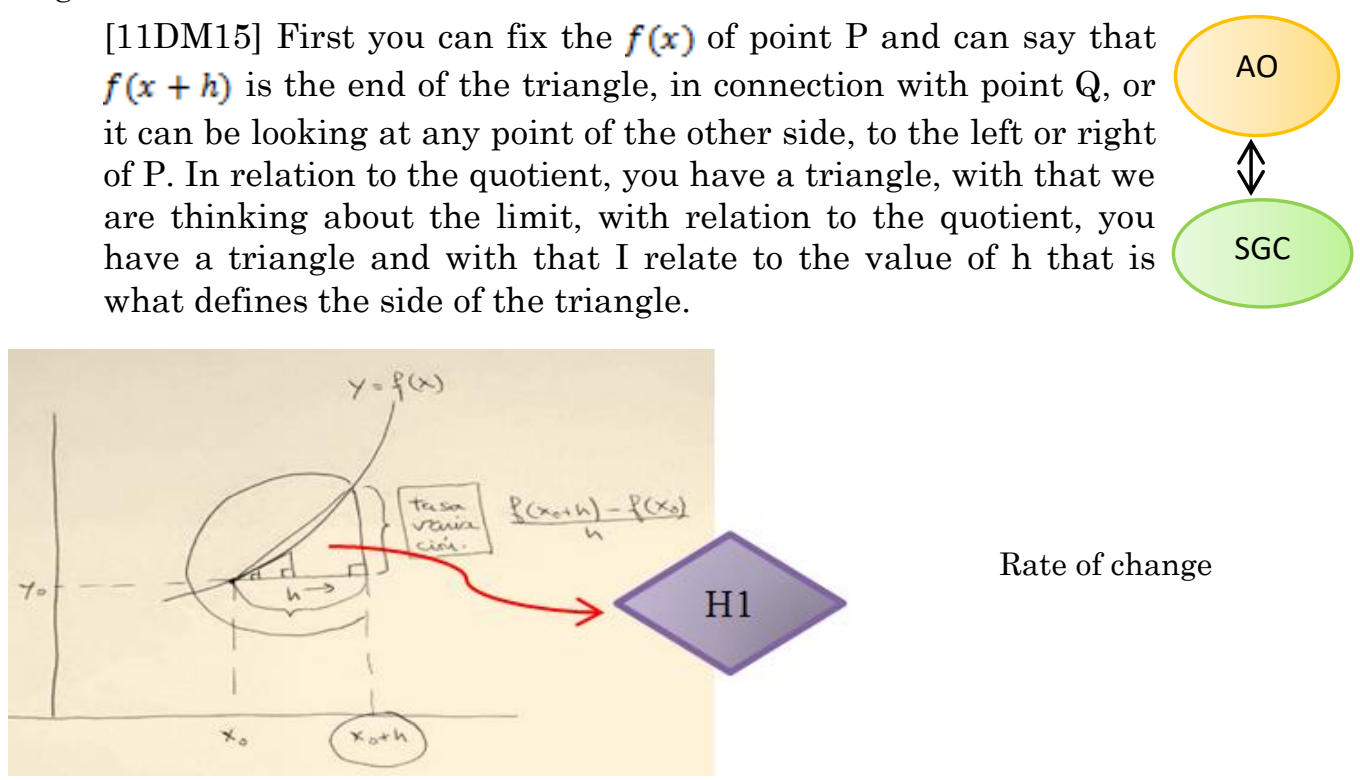

Figure 13 Graphic record of DM15, in relation to the articulator of the SGC mode to the AO mode.

The angle of tangency gives exactly the slope of the tangent line, when $\mathrm{h}$ tends to cero (Figure 13). For me, the concept that connects both is perfectly the right-angle triangle, because I am implicitly using [sic] that the angle is formed between two sides of the triangle. 
The reference of the interviewee to connection, is interpreted as if DM15 is thinking of an articulator between the $\mathrm{AO}$ and SGC modes. In relation to this articulator, DM15, he reflects the following:

[30DM15] I build the definition with an example of the median speed, refining until arriving to the concept, with a specific case, I construct the right-angle triangle until I get to the formal definition, take the diagram and explain with the triangle the mathematical idea. Speed is a tangible stimulus to understand the derivative, but there are students that do not understand from the concrete, it is rare, but it happens.

\section{Identifying the articulator between $A O$ and $A E$}

In relation to the articulator between modes $\mathrm{AO}$ and $\mathrm{AE}$, the arguments given by the informants, show that they identify the slope of the tangent line as an element that relates these two modes. In Figure 14, there is evidence of this.

[27DM16] If you have the limit, as in card 2, then you know it is the value of the slope in the point and then having the equation of the line, you can conclude... [Pause]...that is the slope of the line that is the best approximation to the function at that point.

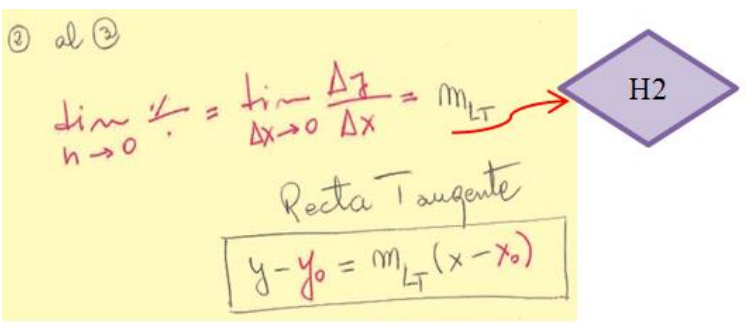

Tangent line

Figure 14 Graphic record of DM16, in relation to the articulator of AO mode to AE mode.

After several minutes of reflection, the informant proposes the slope of the tangent line, as the element that will allow to move from the limit (AO) to the linear approximation (AE) and for this considers the following:

If $\mathrm{f}(\mathrm{x})$ is a function, it can be proved that if:

$$
\begin{aligned}
& g(h)=f\left(x_{0}+h\right)-f\left(x_{0}\right) \quad \text { Since } g(h)=L+r(h) \\
& L \text { is the lineal part } \\
& \text { This quotient is cero } \\
& \frac{r(h)}{\hbar}=\frac{g(h)-L h}{\hbar} \\
& \frac{r(h)}{h}=\frac{f\left(x_{0}+h\right)-f\left(x_{0}\right)-L h}{h} \quad \lim _{h \rightarrow 0} \frac{f\left(x_{0}+h\right)-f\left(x_{0}\right)}{h}=L
\end{aligned}
$$


In his production, the DM16 informant proves that the limit is this linear function and that the tangency point corresponds exactly to the derivate of the function in the point.

\section{Identifying the articulator between AE and SGC}

The three interviewees consider that having the equation of the tangent line in each point makes possible to recover the graphic of the function, and this is achieved by observing the value of the slope of the tangent line (SG) in various sections, in relation to the behavior of the graphic of the function.

[45DM15] If you consider two points that are near, then having the slope of each tangent that approximates the curve, in each instant, I mean in each point, you can soften the curve, taking closer point each time... [Pause]...the curve is completely recovered, of course, it is like that, absolutely.

This last point in a very good diagram by informant DM15 in Figure 15.

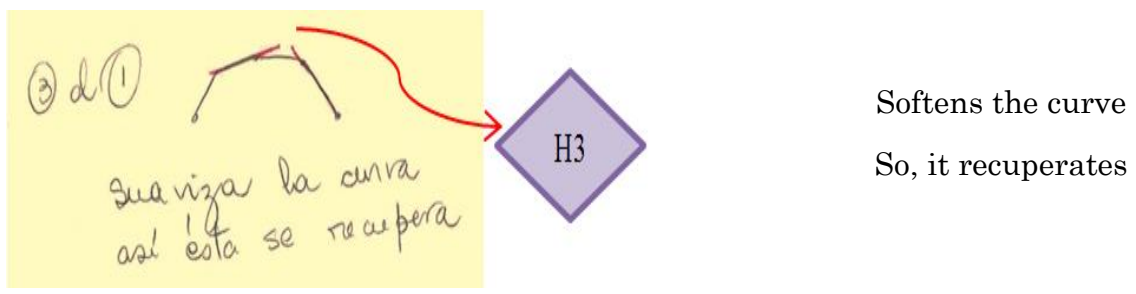

Figure 15 Graphic record of DM15, in relation to the articulator of the SGC mode to AE mode.

\section{Discussion}

The concept of the derivative is a fundamental mathematical object in calculus, and this study has allowed to concentrate interest in the understanding of its local aspect. To describe how students display it, we have focused in a design of understanding, supported by a historical and epistemological analysis, that has been summarized in the SGC, AO and AE modes, which allow, from the analysis of the observable arguments of informants, for the interpretation of their productions from this comprehension design.

Interaction between immediate and reflective actions in the questions applied to Cases 1 and 2, accounted for a partial analytical thought, made evident in questions three and four, in which students needed to know the best approximation. However, it was not a part of their mathematical knowledge, meaning that, the analytical thought that is operational and structural for this design was not achieved by the students. Consequently, the AE mode considered in this research, shows that the informants are weak in relation to a deep comprehension of the concept under study. The inclusion of the AE mode in this design contributes to re-interpret the description that the students performed in Cases 1 and 2 of the derivative linked to the tangent line, in the sense of expanding the conditions of use the derivative has, with the purpose of being applied in more in-depth analysis in other areas of knowledge. In fact, the $\mathrm{AE}$ 
mode is not explicitly considered in the topics of the study programs of differential calculus for the first years of university. However, research based on evidence shown in Case 3 considers the $\mathrm{AE}$ mode to be fundamental to achieve a deep understanding of the mathematical object in question.

1) In the context of the research questions laid out, the thinking modes about the concept in question -SGC, $\mathrm{AO}$ and $\mathrm{AE}-$, after the analysis of the obtained results, shows that the informants of this study have evidenced the following articulators and displayed some associated difficulties.

2) The right-angle triangle in the system of coordinates as an articulating element between $\mathrm{AO}$ and $\mathrm{SGC}$, it is validated when contrasting hypothesis $\mathrm{H} 1$ with the data provided by the interview analysis of Case 3 , this is, to consider a proximity of the point (local aspect) where each point near the $\mathrm{P}$ given point, determines a secant and this in turn determines the right-angle triangle with $\mathrm{h}$ base, represented through the angle of tangency and the slope of the tangent line that geometrically corresponds to the derivative of the function at the point. This information was provided by the informants in the interviews of moment 2 , that totally agrees with the proposed hypothesis, so the triangle shown in Figure 13 is consolidated as an articulator between SGC and AO. In relation to this articulator the difficulties shown by the informants of Cases 1 and 2 are evidenced in the answer to question 2 . When students are situated in the AO mode, the quotient shown in Figure 8 was necessarily related to the limit, as a property of the function without considering the relation with the given quotients. This fact prevented them from showing the idea of approximation in a graphic manner, making it impossible to observe the limit in connection with the geometrical. This comes to strengthen the idea of conceiving the approximation associated directly to limit algebraic calculations (Zandieh, 2000). The students of Cases 1 and 2, situated in the SGC mode, were not able to articulate the $\mathrm{AO}$ mode, in this sense, the production of PM7, in the figure 8, is an evidence of this. It shows elements of the two modes; however, the articulating element was not observed. Question number four was resolved by Cases 1 and 2 from the AO modes, without differentiating between median and instant speeds, similar to what happened in question two. This indicates that there is no understanding of the local aspect of the derivative, because the median speed is a quotient of differences or median exchange rate and students evidence that they confuse these two concepts (Sanchez-Matamoros et al. 2008), a fact that has emerged in this research as an obstacle that generates a weak understanding of the slope of the secant lines as a quotient in relation to the limit.

3) The slope of the tangent line as an articulator between $\mathrm{AO}$ and $\mathrm{AE}$ was validated when contrasting $\mathrm{H} 2$ hypothesis with the data provided by the informants in Case 3. It was not explicitly shown in the observable arguments of students in Cases 1 and 2; furthermore, they did not know that the derivative could be represented as the slope of the tangent line that approximates the function in a proximity of the point, in fact these informants did not respond part b) of question three of the questionnaire that refers to the AE mode. This is related closely to the research carried out by Sierpinska, Nnadozie and Oktaç, (2002) in the sense that when the situation to be solved is mathematical, it can be a common theoretical thought among mathematicians, but not in the case of 
students, since they need tools that will allow them to achieve abstraction of the mathematical object.

4) The equation of the tangent line as the articulating element between $\mathrm{SG}$ and $\mathrm{AE}$, is validated when confronting hypothesis $\mathrm{H} 3$ with the data that emerged from the analysis of the interviews of Case 3 . The difficulty in the understanding of the derivative in a SGC mode can be due to a mistaken conception of the tangent line that in teaching is not considered as a notion that must be clarified for the understanding of the derivative. To this respect, Montoya Delgadillo and Vivier (2015), show that university students face the concept of tangency as knowledge that becomes inappropriate, since the students acquire this knowledge of the tangent line for the specific case of the circumference, Euclides definition, acquired in High School that arises again with the derivative, during the first university courses, given that the curves with points of inflection would not have the possibility of a tangent.

A reflection regarding the importance of the deep understanding of the local aspect of the derivative, provided by informant DM15, shows that the focus of this study could be projected to other important concepts of differential calculus, such as the Median Value Theorem, the Rolle Theorem, or other concepts that are pertaining to Mathematics and of immediate consequences in their local aspect.

[30DM15] I have never seen this aspect of the derivative from a local perspective (card 3) in my classes. I have taught calculus I and II courses, and I begin with the idea of cero. The first time that I covered the aspect that card 3 shows (AE mode) of the derivative, was when I started graduate school, but students understand, I think it would be important to teach these three aspects and I also consider that a good understanding of these scheme would allow them to better understand the median value theorem and the Rolle theorem.

This design of the modes of thinking the local aspect of the derivative through SGC, AO and AE (Figure 16), presents independent ways to access the concept, which being in connection through the articulators allows us to describe in-depth understanding of the derivative. However, we also consider that this paradigmatic stance becomes insufficient when the tasks presented to the students do not allow connection between the SGC, AO and AE modes of thinking.

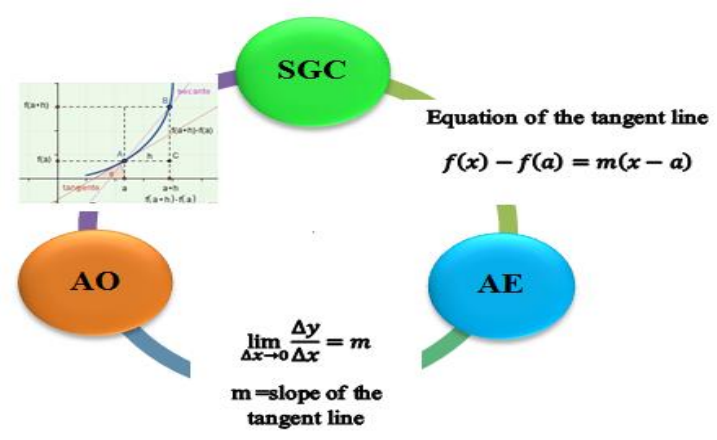

Figure 16 The relationship of the articulators with the thinking modes of the derivative in its local aspect. 
In general, we can say that these thinking modes -SGC, AO and AEalong with their articulators, are proposed as a design for the deep understanding of the derivative in its local aspect, and that has been fundamental to describe them and demonstrate them, a resolution of tasks centered not only around an algebraic paradigm (Vanderbrouck, 2011), but also others that will allow mobility among them. Despite this, the results were as shown in Table 5, students situate themselves in the AO mode and in most of their productions they try to solve the problem in an algebraic manner (Kinley 2016), with no explicit connection with other modes.

To conclude, we consider that the design presented in Figure 16, with its re-interpreted components as the modes of thinking the local aspect of the derivative is linked to the rupture of a purely algebraic thought, and this facilitates the deep understanding of the local aspect of the derivative. This characterization also contributes to the design of classroom activities, and projects itself as a design for understanding to determine if a student has a deep understanding of this concept.

\section{Acknowledgements}

This work was funded by Scientific and Technological Research (CONICYT for its acronym in Spanish)/ the National Doctorate Scholarship award/ Folio: 21161074.

We also acknowledge the willingness of participants in the investigation and the partial funding of the Project DI REGULAR 039.431/2017.

\section{Disclosure statement}

No potential conflict of interest was reported by the authors.

\section{Notes on contributors}

Irma Ercira Pinto-Rojas - Deparment of Mathematic, Universidad Católica del Norte, CHILE

Marcela Cecilia Parraguez González - Mathematics Institute, Pontificia Universidad Católica de Valparaíso, CHILE

\section{References}

Artigue, M. (1995). La enseñanza de los principios del cálculo: problemas epistemológicos, cognitivos y didácticos. In P. Gómez (Ed.), Ingeniería Didáctica en Educación Matemática (pp.97-140). México: Grupo Editorial Iberoamericano.

Bachelard, G. (2000). La formación del espíritu científico. México DF: Siglo XXI.

Badillo, E., Azcárate, C. y Font, V. (2011). Analysis of comprehension levels of objects f'(a) and f'(x) in Mathematics teachers. Enseñanza de las Ciencias, 29(2), 191-206.

Boyer, C. (1959). The History of the Calculus and its Conceptual Development. New York: Dover Publications.

D’Amore, B. and Godino, J. (2007) El enfoque Ontosemiótico como un desarrollo de la teoría Antropológica en Didáctica de la matemática. Revista Latinoamericana de Investigación en Matemática Educativa, 10(002), 191-218. 
Ferrini-Mundy, J. \& Graham, K. (1994). Research in calculus learning: Understanding of limits, derivatives and integrals. In J. Kaput \& E. Dubinsky (Eds.), Research issues in undergraduate mathematics learning (pp. 31-45). Washington: MAA Notes.

Grabiner, J. (1983). The changing concept of change: The derivative from Fermat to Weierstrass. Mathematics Magazine, 56(4), 195-206.

Jaafar, R. and Lin, Y. (2017). Assessment for Learning in the Calculus Classroom: A Proactive Aproach to Engange Students in Active Learning. IEJME-Mathematics Education 12(5), 503520.

Kinley, M. (2016). Grade Twelve Students Establishing the Relationship Between Differentiation and Integration in Calculus Using graphs. IEJME-Mathematics Education, 11(9), 3371-3385.

Lang, S. (1972). Introduction to Differential Manifold. Yale: Springer.

Mena, A., Mena, J., Montoya, E, Morales, A. y Parraguez, M., (2015). El obstáculo epistemológico del infinito actual. The epistemological obstacle of the current infinite. Revista Latinoamericana de Investigación en Matemática Educativa, 18(3), 329-358.

Montoya Delgadillo, E. \& Vivier, L. (2015). ETM de la noción de tangente en un ámbito gráfico Cambios de dominios y de puntos de vista, Proceedings of CIAEM XIV, (pp.5-7), Chiapas: Tuxtla Gutiérrez.

Park, J. (2015) Is the derivative a function? If so, how do we teach it? Educational Studies in Mathematics, 89(2), 233-250.

Parraguez, M. (2012). Teoría los modos de pensamiento. Didáctica de la Matemática. Valparaíso: Ediciones Instituto de Matemática de la Pontificia Universidad Católica de Valparaíso.

Pino-Fan, L., Godino, J. y Font, V. (2011). Faceta epistémica del conocimiento Didáctico-Matemático sobre la Derivada. Educação Matemática Pesquisa, 13(1), 141-178.

Poole, D. (2014). Linear Algebra: A Modern Introduction. New York: Brooks/Cole.

Redon, S. y Angulo, J. (2017). Investigación Cualitativa en Educación. Argentina: Miño y Dávila.

Sánchez-Matamoros, García, G., García Blanco, M., and Llinares Ciscar, S. (2008). El desarrollo del esquema de derivada. Enseñanza de las ciencias. Revista de investigación y experiencias didácticas, 24(1), 85-98.

Sfard, A. (1991). On the Dual Nature of Mathematical Conceptions: Reflections on Processes and Objects as Different Sides of the Same Coin. Educational Studies in Mathematics, 22(1), 136.

Sierpinska, A. (1985). Obstacles épistémologiques relatifs à la notion de limite. Recherches en Didactique des Mathématiques, 6(1), 5-67.

Sierpinska, A. (2000). On some Aspects of Student's thinking in Linear Algebra. In J. Dorier.(Ed.), The Teaching of Linear Algebra in Question (pp. 209-246). Netherlands: Kluwer Academic Publishers.

Sierpinska, A. (2005) On Practical and Theoretical Thinking and Other False Dichotomies in Mathematics Education. In M.H. Hoffmann, J. Lenhard, F. Seeger. (Ed) Activity and Sign (pp.117-135). Boston: Springer.

Sierpinska, A., Nnadozie, A. y Oktaç, A. (2002) A Study of relationships between theoretical thinking and high achievement in linear algebra. Concordia University: Montreal.

Stake, R. (2010). Investigación con estudio de casos. Madrid: Morata.

Steward, I. (2007). Historia de las matemáticas en los últimos 10.000 años. España: Drakontos.

Tallman, M., Carlson, M. P., Bressoud, D., \& Pearson, M. (2016). A characterization of calculus I final exams in U.S. colleges and universities. International Journal of Research in Undergraduate Mathematics Education, 2(1), 105-133.

Vandebrouck, F. (2011). Perspectives et domaines de travail pour l'étude des fonctions. Annales de Didactique et de Sciences Cognitives, 16(1), 149-185.

Zandieh, M. (2000). A theoretical framework for analyzing student understanding of the concept of derivative. In E. Dubinsky, A. Schoenfeld, J. Kaput, (Ed.), Research in collegiate mathematics education. IV. Issues in mathematics education (pp. 103-127). Providence, RI: American Mathematical Society.

Zimmermann, W. y Cunningham, S. (1991). Visualisation in Teaching and Learning Mathematics. Washington DC, USA: Mathematical Association of America. 